screening in pregnancy, with the now-a-day available point-ofcare tests, and treating within the same visit with at least one dose of penicillin.

\section{P3.354 VERTICAL TRANSMISSION OF SYPHILIS: CURRENT REALITY IN THE CITY OF BAURU}

doi:10.1136/sextrans-2013-051184.0807

I M Lira Pelegrina. Centro de Referência em Moléstias Infecciosas, Bauru, Brazil

Introduction Syphilis, a sexually transmitted disease caused by Treponema pallidum transmitted vertically during pregnancy, resulting in congenital syphilis.

Methodology This study results from a qualitative study from the research of statistical Information System for Notifiable Diseases SINAN, through the Division of Surveillance, the Municipal Health Secretariat of Bauru, referring to pregnant women with syphilis diagnosed during the prenatal period March 2009 to December 2011, residents in the city of Bauru, and the growing number of cases reported annually.

Results In 2009, 15 cases were reported of syphilis in pregnant women, and $3(20 \%)$ resulting in congenital syphilis. In 2010, there were 24 reported pregnancy resulting in 9 cases of congenital syphilis reported (37.5\%). In 2011, there were 33 reported cases of syphilis in pregnant women, and 17 cases of congenital syphilis (51.5\%). In 2011, of the 33 cases of syphilis in pregnant women, 14 of them were reported by Santa Izabel Hospital at delivery, fetal death being 1 and 5 miscarriages.

Conclusion The results show an increasing number in the last 3 years, confirming the reality for the city of Bauru, which equates to the epidemiological profile of the State of São Paulo. The notification by the epidemiological surveillance all syphilis cases ensures epidemiological measures of disease control. The increasing cases pointed to the need to evaluate in detail the data to have knowledge of the scale of the problem, whether the late onset of the inadequate treatment of syphilis or even underreporting to develop control measures and planning of health policies public aimed at elimination of the disease.

\section{P3.355 COINCIDENCE OF SYPHILIS AND PREGNANCY IN SZABOLCS-SZATMÁR-BEREG COUNTY BETWEEN 1990-2011}

doi:10.1136/sextrans-2013-051184.0808

'V Várkonyi, ${ }^{1,2} \mathrm{G}$ Szondy, ${ }^{1,3} \mathrm{~K}$ Együd, ${ }^{1,4} \mathrm{M}$ Dudás. ${ }^{1}$ Privat Praxis, Budapest, Hungary; ${ }^{2} J o ́ s a$ András Hospital Departmen of DV, Nyíregyháza, Hungary; ${ }^{3} J o ́ s a$ András Hospital Department of DV, Nyíregyháza, Hungary; ${ }^{4}$ National Centre for Epidemiology, Budapest, Hungary

The treatment of infected cases, active case finding and the followup are the tasks of the dermato-venereological network. Since data on treated syphilis cases were available from decades back, a retrospective analysis was done.

Objective Syphilis patients treated between 1990-2011 in Szabolcs-Szatmár-Bereg county compared with national data, with the following criteria:

- Changes in morbidity in the county and in the country with sex distribution,

- Analysis by age group among women, especially during pregnancy,

- Distribution by diagnosis in women and in pregnant women including the trimester,

Results between 1990-2011, the outpatient clinic in SzabolcsSzatmár-Bereg county treated a total of 469 syphilis cases (women $\mathrm{n}=243 / 52 \% /$, male $\mathrm{n}=226 / 48 \% /$ ),

- out of 243 patients, 69 had applied the syphilis diagnosis during pregnancy,
- The diagnosis of syphilis among pregnant women was as follows: primary syphilis $1 / 1.5 \% /$, secondary syphilis: $17 / 25 \% /$, early latent: $48 / 69.5 \% /$, late latent: $3 / 4 \% /$.

- between 1990-2000 the syphilis occurred sporadically among pregnant women, the number of however the cases between 2003-2008 increased significantly (in 1990-2000 $\mathrm{n}=6$; in 2001-2011 years $n=63$ ),

- According the age group distribution, syphilis infection in pregnant women were most common in the 20-34 agegroup $(20-24 / 30 \% /, \quad 25-29 / 20 \% \%, 30-34 / 23 \% /)$ and the $15-19$ age group was also affected (16\%)

- In terms of ethnicity, $49 \%$ of pregnant women ( $n=34)$ was roma, $22 \%$ of them was from Ukraine, $(n=15)$ and $29 \%$ of them was Hungarian $(\mathrm{n}=20)$,

\section{Conclusions}

The following factors played a role in spreading of syphilis in Szabolcs-Szatmár-Bereg county

- The county's geographic location.

- Significant illegal prostitution (cross-border, massage parlours, roadside, living prostitution),

- The lack of knowledge of the professions about syphilis

- Lack of knowledge of the population

\section{P3.356 SYPHILIS SCREENING AMONG 27150 PREGNANT WOMEN IN RURAL SOUTHERN CHINA USING POINT-OF-CARE TESTS}

doi:10.1136/sextrans-2013-051184.0809

${ }^{1} \mathbf{L}$ Yang, ${ }^{1,2} \mathrm{~J}$ Tucker, ${ }^{1} \mathrm{~F}$ Liu, ${ }^{1} \mathrm{X}$ Ren, ${ }^{1} \mathrm{H}$ Xuan, ${ }^{1} \mathrm{C}$ Wang, ${ }^{1} \mathrm{C}$ Bien, ${ }^{3} \mathrm{X}$ Chen, ${ }^{1} \mathrm{~B}$ Yang. ${ }^{1} G u a n g d o n g$ Provincial Center for STI Control \& Prevention, Guangzhou, China; 2University of North Carolina at Chapel Hill, Chapel Hill, NC, United States; ${ }^{3}$ National Center for STD Control, Nanjing, China

Background Guangdong province in southern China is at the centre of a national syphilis epidemic, with a tenfold increase of reported syphilis cases in the past ten years. However, the epidemic remains poorly described in rural areas of Guangdong, where hygiene stations (community-level clinics) lack the capacity to undertake routine prenatal syphilis screening. The purpose of this research was to determine the prevalence of syphilis and its risk factors among pregnant women, and to assess the acceptability of point-of-care tests in resource-limited areas of Guangdong province. Methods From June 2010 to April 2012, we invited 55 hygiene stations, 12 general hospitals, and four women and children's hospitals in resource-limited areas of Guangdong province to participate in the study. Free point-of-care syphilis testing were provided to each of the study sites, and positive samples were confirmed at local referral centres by toluidine red unheated serum test (TRUST)) and Treponema pallidum particle agglutination (TPPA) test. Confirmed cases received free treatment with benzathine penicillin.

Results A total of 27,150 pregnant women were screened for syphilis by point-of-care syphilis tests, $106(0.39 \%)$ syphilis cases were diagnosed, of which 78 cases $(73.6 \%)$ received treatment for syphilis. Syphilis infection among pregnant women was associated with older age and a previous history of adverse pregnancy.

Conclusions Syphilis infection is a significant problem among pregnant women living in rural areas of southern China. Point-ofcare syphilis testing was well accepted in resource-limited settings, and can increase case detection in rural areas with limited testing capacity.

\section{P3.357 INTEGRATION OF RAPID SYPHILIS TESTING INTO ROUTINE ANTENATAL SERVICES IN RURAL KENYA: SUCCESSES AND CHALLENGES}

doi:10.1136/sextrans-2013-051184.0810

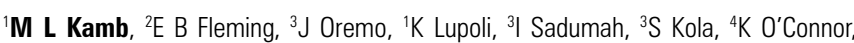
${ }^{5} \mathrm{M}$ Kelley, ${ }^{4} \mathrm{R}$ Quick, ${ }^{6} \mathrm{Y}$ Tun. 'Division of STD Prevention, CDC, Atlanta, GA, United 